\title{
SOEP
}

SOEPpapers

SOEPpapers
on Multidisciplinary Panel Data Research

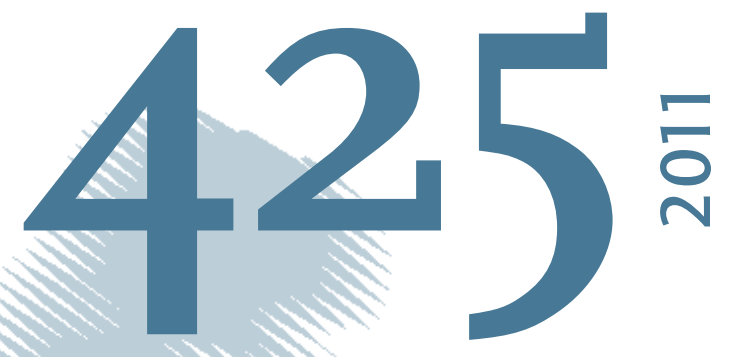

\section{Multidimensional Well-Being at the Top: Evidence for Germany}




\section{SOEPpapers on Multidisciplinary Panel Data Research}

at DIW Berlin

This series presents research findings based either directly on data from the German SocioEconomic Panel Study (SOEP) or using SOEP data as part of an internationally comparable data set (e.g. CNEF, ECHP, LIS, LWS, CHER/PACO). SOEP is a truly multidisciplinary household panel study covering a wide range of social and behavioral sciences: economics, sociology, psychology, survey methodology, econometrics and applied statistics, educational science, political science, public health, behavioral genetics, demography, geography, and sport science.

The decision to publish a submission in SOEPpapers is made by a board of editors chosen by the DIW Berlin to represent the wide range of disciplines covered by SOEP. There is no external referee process and papers are either accepted or rejected without revision. Papers appear in this series as works in progress and may also appear elsewhere. They often represent preliminary studies and are circulated to encourage discussion. Citation of such a paper should account for its provisional character. A revised version may be requested from the author directly.

Any opinions expressed in this series are those of the author(s) and not those of DIW Berlin. Research disseminated by DIW Berlin may include views on public policy issues, but the institute itself takes no institutional policy positions.

The SOEPpapers are available at

http://www.diw.de/soeppapers

\section{Editors:}

Joachim R. Frick (Empirical Economics)

Jürgen Schupp (Sociology, Vice Dean DIW Graduate Center)

Gert G. Wagner (Social Sciences)

Conchita D'Ambrosio (Public Economics)

Denis Gerstorf (Psychology, DIW Research Professor)

Elke Holst (Gender Studies)

Frauke Kreuter (Survey Methodology, DIW Research Professor)

Martin Kroh (Political Science and Survey Methodology)

Frieder R. Lang (Psychology, DIW Research Professor)

Henning Lohmann (Sociology, DIW Research Professor)

Jörg-Peter Schräpler (Survey Methodology, DIW Research Professor)

Thomas Siedler (Empirical Economics, DIW Graduate Center)

C. Katharina Spieß (Empirical Economics and Educational Science)

ISSN: 1864-6689 (online)

German Socio-Economic Panel Study (SOEP)

DIW Berlin

Mohrenstrasse 58

10117 Berlin, Germany

Contact: Uta Rahmann | soeppapers@diw.de 


\title{
Multidimensional Well-Being at the Top: Evidence for Germany
}

\author{
Andreas Peichl \\ IZA, University of Cologne, ISER and CESifo \\ Nico Pestel \\ IZA and University of Cologne
}

\begin{abstract}
This paper employs a multidimensional approach for the measurement of well-being at the top of the distribution using German SOEP micro data. Besides income as traditional indicator for material wellbeing, we include health as a proxy for nonmaterial quality of life as well as self-reported satisfaction with life as dimensions. We find that one third of the German population is well-off in at least one dimension but only one percent in all three dimensions simultaneously. While the distribution of income has become more concentrated at the top, the concentration at the top of the multidimensional well-being distribution has decreased over time. Moreover, health as well as life satisfaction contribute quite substantially to multidimensional wellbeing at the top which has important policy implications.
\end{abstract}

JEL Classification: D31, D63, I31

Keywords: multidimensional measurement, well-being, Germany

\section{Corresponding author:}

Nico Pestel

IZA

P.O. Box 7240

53072 Bonn

Germany

E-mail: pestel@iza.org 


\section{Introduction}

The Stiglitz report on the measurement of economic performance and social progress recognizes that "well-being is multidimensional" (Stiglitz et al., 2009, p. 14). Indeed, in recent years, research in particular on poverty and inequality has considerably advanced with respect to theoretical as well as empirical implications of considering multiple dimensions at the same time (see Atkinson, 2003; Bourguignon and Chakravarty, 2003; Alkire and Foster, 2011a; Decancq and Lugo, 2011a, among others). At the same time, the literature on economic inequality has given increasing attention to the top of the (income) distribution (see e.g. Piketty (2005), Piketty and Saez (2006), Atkinson and Piketty (2007) and Atkinson et al. (2011) for overviews). Waldenström (2009) argues that "the rich" are an important group in society and that the resources of the very top are important sources of variation in measures of inequality. So far, however, the recent top income literature has only been concerned with a single dimension (in particular income and to a lesser extent wealth). Therefore, Peichl and Pestel (2011) combine the two strands in the literature and propose a class of multidimensional richness measures by extending the onedimensional richness indices developed by Peichl et al. (2010). This approach is related to the work of Alkire and Foster (2011), who extend the Foster-GreerThorbecke (FGT) poverty measures (Foster et al., 1984) to a multidimensional setting. Central to this is a dual cutoff method that identifies those individuals considered to be multidimensionally well-off. Hence, the joint distribution of dimensions under consideration is explicitly taken into account. In this paper, we apply the approach laid out in Peichl and Pestel (2011) to the top of the multidimensional distribution of well-being in Germany using data of the German Socio-Economic Panel Study (SOEP) for 2002 and 2007. ${ }^{1}$

A multidimensional approach raises the question which dimensions should be considered (cf. Decancq and Lugo, 2011b). Stiglitz et al. (2009) have identified various key dimensions that should in principle be taken into account, when providing a more differentiated picture of a society's economic well-being. These dimensions comprise, among others, material living standards and health. Moreover, it is argued that quality of life depends on people's objective conditions and capabilities as well as

\footnotetext{
${ }^{1}$ See Peichl and Pestel (2011) for a detailed description of the methodology. The application there considers the joint distribution of income and wealth in Germany and the US.
} 
on their subjective evaluations (cf. Anand and van Hees, 2006). Here, we seize on these recommendations and apply the approach of Peichl and Pestel (2011) to income as a key indicator for material living standards, an objective health measure taking into account non-financial aspects of quality of life and self-reported life satisfaction as dimensions - reflecting different domains of life. Analyzing the joint distribution of these dimensions reveals additional insights about the determinants of well-being at the top. Moreover, we are able to quantify the contribution of each dimension to multidimensional well-being.

Our empirical analysis yields the following results. We find that it is necessary to take a multidimensional approach since income is by far not perfectly correlated with the other dimensions of well-being under consideration here. One third of the population is well-off in at least one dimension but only one percent in all three dimensions simultaneously. Furthermore, while the distribution of income has become more concentrated at the top, the concentration at the top of the multidimensional wellbeing distribution has decreased. Moreover, health as well as life satisfaction turn out to contribute quite substantially to multidimensional well-being at the top.

The paper is organized as follows: Section 2 introduces the concept of measuring multidimensional well-being and the data. Our results are presented in section 3 . In section 4 we discuss possible extensions as well as some implications of a multidimensional approach. Section 5 concludes.

\section{Measurement and Data}

Methodology. The dual cutoff method of multidimensional well-being works as

follows: In a first step, an individual is considered as dimension-specific well-off when its achievement in a specific dimension exceeds the respective cutoff value. In a second step, we define which individuals (among those who are well-off with respect to at least one dimension) are considered to be affluent in a multidimensional sense with the help of a counting methodology (Atkinson, 2003; Alkire and Foster, 2011a). An individual is defined to be multidimensionally well-off, if the number of affluence counts across all dimensions is greater than or equal to a certain threshold (second 
cutoff). After having identified the well-off subpopulation, their individual achievements are aggregated to a single-value measure of multidimensional wellbeing. $^{2}$

Formally, we consider a population with $n$ individuals denoted $i=1, \ldots, n$ and $d \geq 2$ dimensions of well-being $\mathrm{j}=1, \ldots, \mathrm{d}$. An individual $\mathrm{i}$ 's achievement in dimension $\mathrm{j}$ is denoted $y_{i j}$. For each dimension $j$, there is some cutoff value $\gamma_{j}$ and hence we can define an indicator function $\theta_{\mathrm{ij}}$ equal to one if $\mathrm{y}_{\mathrm{ij}}>\gamma_{\mathrm{j}}$ and zero otherwise. Hence, for each individual we can add up the number of dimensions in which he or she is welloff to $\mathrm{c}_{\mathrm{i}}=\Sigma_{\mathrm{j}} \theta_{\mathrm{ij}}$. Whether an individual is multidimensionally well-off is identified according to the dual cutoff method. For an integer $\mathrm{k}=1, \ldots, \mathrm{d}$ we define another indicator $\varphi_{\mathrm{i}}(\mathrm{k})$ equal to one if $\mathrm{c}_{\mathrm{i}} \geq \mathrm{k}$ and zero otherwise. In other words, individual $\mathrm{i}$ is considered to be multidimensionally well-off, if the number of well-off dimensions attains a certain threshold. The total number of the well-off subpopulation is $\mathrm{s}(\mathrm{k})=\Sigma_{\mathrm{i}}$ $\varphi_{i}(\mathrm{k})$. Since, according to the focus axiom, a measure shall only take into account information on the well-off, we ignore the number of well-off dimensions of those individuals (i.e. replace them with zero), when the individual numbers of counts do not attain the threshold $\mathrm{k}$. Formally $\mathrm{c}_{\mathrm{i}}(\mathrm{k})=\mathrm{c}_{\mathrm{i}}$ whenever $\varphi_{\mathrm{i}}(\mathrm{k})=1$ and zero otherwise. That is, even in case of an individual being well-off in several dimensions, the relevant number of counts $c_{i}(k)$ might be zero if the number of well-off dimensions is smaller than the threshold $\mathrm{k}$. In order to define a multidimensional measure of wellbeing, define the headcount ratio as

$$
\operatorname{HR}(\mathrm{k})=\frac{\mathrm{s}(\mathrm{k})}{n},
$$

which is simply the proportion of multidimensionally well-off individuals among the total population. The average affluence share reads

$$
A A S(k)=\frac{\sum_{i} c_{i}(k)}{s(k) \cdot d},
$$

which is equal to the relation of the number of well-being counts to the maximum number of counts that would be observed when all well-off individuals had a count equal to $\mathrm{d}$. We define the dimension adjusted headcount ratio as

\footnotetext{
${ }^{2}$ See Peichl and Pestel (2011) for a more detailed and more formal description of the methodology.
} 


$$
H R^{M}(k)=H R(k) \cdot A A S(k)=\frac{\sum_{i} c_{i}(k)}{n \cdot d},
$$

which is equal to the proportion of the total number of well-being counts to the maximum number of counts that one would observe when every single individual in the population would be well-off with respect to every single dimension. Contrary to the simple headcount ratio $\mathrm{HR}(\mathrm{k})$, the index $\operatorname{HR}^{\mathrm{M}}(\mathrm{k})$ satisfies the property of dimensional monotonicity, i.e. it increases (decreases) when a multidimensionally well-off individual $\left(\mathrm{c}_{\mathrm{i}} \geq \mathrm{k}\right)$ becomes (is no more) well-off in some dimension. In addition, Peichl and Pestel (2011) propose measures that also satisfy the property of monotonicity, which means that the measure is also responsive to changes in the level of achievements and explicitly takes into account inequality at the top of the joint distribution.

Data. The German Socio-Economic Panel Study (Wagner et al., 2007; SOEP, 2011) is a panel survey of households and individuals in Germany that has been conducted annually since 1984 . We use the 2002 and 2007 waves of the SOEP with information of around 20,000 individuals (aged 16 and older) in about 11,000 households. In order to improve its "statistical power" and the reliability of statements referring to high incomes (and hence affluence), an additional sample of high income households was included into the SOEP since wave 2002. This increased the number of observations within the top $2.5 \%$ of the income distribution considerably and hence reduced potential bias due to poor representativeness of affluent households. Since these additional observations were oversampled, population weights were adjusted accordingly to make the data representative for the German population (Frick et al., 2007). The SOEP income data has been validated against administrative tax data and was found to perform reasonably well up to the top $1 \%$ of the income distribution (Bach et al., 2009).

Income. Our income measure contains market and transfer income from various sources as well as private transfers and pensions from all household or family members net of total tax and social security contribution payments of all household members (Grabka, 2009). We use the square root equivalence scale for equivalence weighting in order to make incomes of individuals living in different-size households comparable to each other. Values are expressed in real terms (2005 euros). 
Health. The indicator for an individual's overall health status we apply relies on two generally accepted and widely used health measures: the Mental Component Scale (MCS) and the Physical Component Scale (PCS), the so-called SF-12v2TM indicators. These measure eight domains of health in total, which are grouped into two dimensions of mental and physical health respectively. ${ }^{3}$ The values are normalized in a way that the mean equals 50 and the standard deviation a value of 10 in the base year 2006. This makes the levels comparable not only within the cross section but also over time. Our health measure is just the mean of the measures for mental and physical health (MCS and PCS).

Overall Life Satisfaction. Every respondent in the SOEP is asked to indicate how satisfied he or she is with life in general at the time of the survey. Individuals report this on an eleven-point Likert-type scale of zero to ten, with zero meaning completely dissatisfied and ten completely satisfied (cf. Grabka, 2009). This is the widely used way of measuring satisfaction with life but also satisfaction with various domains of life, which has been employed in numerous empirical studies on overall life staisfaction.

Cutoffs. Defining the cutoffs which separate the population into affluent and nonaffluent individuals with respect to the dimensions under consideration is crucial for the empirical analysis. Although there are several ways to draw a poverty line (relative vs. absolute), the underlying principle - a poor person does not meet a certain level of subsistence, while a non-poor one does - is uncontroversial. With respect to the top of the distribution this is less clear. The decision how to define cutoffs is up to the researcher and has to be based on normative grounds. Barry (2002, p. 28) suggests an "upper threshold" for income at a value of three times the median. We follow Peichl et al. (2010), who, in a similar way, suggest a cutoff value for income of $200 \%$ of the median for Germany. For the other dimensions, we choose $110 \%$ each for health and life satisfaction (rounded in case of life satisfaction). Moreover, since all dimensions under consideration (especially income and health) usually exhibit distinct profiles over the life cycle, we let the cutoffs vary by age of

\footnotetext{
${ }^{3}$ See Nübling et al. (2007) for a detailed description of the computation of the SOEP version of SF$12 \mathrm{v} 2$ health measures.
} 
the household head and distinguish three age groups (head aged $\leq 29,30-59$ and $\geq$ $60)$.

\section{Results}

Descriptives. Table 1 contains the descriptive statistics of the dimensions under consideration as well as the cutoff levels for both years. The level of mean and median income (in real terms) has not changed much between 2002 and 2007: Overall mean income is around 22,500 euros while the overall median is lower with a level of around 19,000 euros. The cutoff levels - i.e. $200 \%$ of the age group specific median clearly display an inverse U-shape pattern: The youngest group (household head younger than 30) reveals the lowest cutoff level at 27,000-29,000 euros and it increases to around 41,000 euros for the middle aged group. The income cutoff is lowest for the group above 60 years at around 35,000 euros. While the overall means, medians as well as the cutoff levels have remained rather stable during the 2002-2007 period, the fraction of the population with incomes above the cutoff level - i.e. the well-off in terms of income - has clearly increased from $8.5 \%$ to $9.3 \%$. This is in line with growing income inequality especially at the top of the income distribution in Germany (cf. Bach et al., 2009; Peichl et al., 2010).

Table 1: $\quad$ Descriptive statistics and cutoffs

\begin{tabular}{lccccccc}
\hline Year & Dimension & Mean & Median & \multicolumn{3}{c}{ Cutoff (by age group) } & \% well-off \\
& & & & $\leq \mathbf{2 9}$ & $\mathbf{3 0}-\mathbf{5 9}$ & $\mathbf{2 6 0}$ & \\
\hline 2002 & Income & 22,670 & 19,045 & 29,234 & 41,133 & 34,315 & 8.5 \\
& Health & 49.1 & 50.2 & 57.6 & 56.6 & 51.8 & 21.0 \\
& Satisfaction & 6.9 & 7 & 8 & 8 & 8 & 15.2 \\
\hline 2007 & Income & 22,549 & 18,831 & 26,678 & 40,442 & 35,095 & 9.3 \\
& Health & 49.4 & 50.7 & 58.3 & 57.0 & 52.9 & 17.9 \\
& Satisfaction & 6.9 & 7 & 9 & 8 & 8 & 15.4 \\
\hline \hline
\end{tabular}

Source: SOEP, own calculations.

The average level of health - both in terms of mean and median - is around 50 for both years, which is not surprising given the calibration of the summary indices. The age specific medians and hence the respective cutoff levels show a clear pattern, which is decreasing over the life cycle, since younger individuals are much healthier on average. The drop in the health cutoff is especially sharp between the middle aged 
group and the oldest subgroup (from around 57 to 52-53). At the same time, health of all subgroups has improved between 2002 and 2007, which automatically results in slight increases in cutoff levels. Moreover, the population's percentage with health levels above the respective cutoffs has decreased by three percentage points from $21 \%$ to $18 \%$.

Finally, overall life satisfaction has remained rather stable on average in Germany at a value of around seven on the scale between zero and ten. The cutoff level is eight for all subgroups in 2002 and increases only for the youngest group to a level of nine. The fraction of the most satisfied individuals has consequently remained identical over time at around $15 \%$ of the population.

Correlations. The key motivation for research on multiple dimensions is that income does not fully capture all determinants of (economic) well-being. Implicitly, this means that income is not a perfect predictor of well-being and therefore not perfectly correlated with the other dimensions under consideration. Hence, we take a closer look at the relationship between the dimensions under consideration here. The pair wise correlation coefficients are displayed in Table 2 . We find that income indeed reveals rather low levels of correlation with health and life satisfaction of below 0.1 and below 0.2 respectively. At the same time the correlation between health and overall life satisfaction is distinctly larger (above 0.4 and 0.5 respectively), since good health is one of the most important determinants of satisfaction in general (cf. Blanchflower and Oswald, 2011).

Table 2: $\quad$ Correlations between dimensions

\begin{tabular}{lcccc}
\hline \hline Year & Dimension & Income & Health & Satisfaction \\
\hline 2002 & Income & 1 & & \\
& Health & 0.086 & 1 & 1 \\
& Satisfaction & 0.103 & 0.531 & \\
\hline 2007 & Income & 1 & & 1 \\
& Health & 0.096 & 1 & \\
& Satisfaction & 0.138 & 0.443 & \\
\hline \hline
\end{tabular}

Source: SOEP, own calculations.

Hence, we conclude that it is indeed justified to take a multidimensional approach since income is rather poorly correlated with other dimensions that are argued to contribute to economic well-being. 
Multidimensional well-being. Before turning to our results on multidimensional well-being at the top we first display the distribution of the number of well-off counts in the upper panel of Table 3. It turns out that in both years under consideration about $65 \%$ of the population is not well-off in any dimension, about $25 \%$ in exactly one and about $8-9 \%$ in two dimensions. Only a mere $1 \%$ is well-off in all three dimensions simultaneously.

Our results for the dimension adjusted headcount ratio (cf. equation (3)) of multidimensional well-being at the top of the joint distribution of the three dimensions under consideration are displayed in the lower panel of Table 3 for the 2002 and 2007 waves of the SOEP. We differentiate between the different levels of the second stage cutoff $k$, i.e. the required number of well-off dimensions in order to define an individual to be multidimensionally well-off. While one third of the population (35\%) is well-off in at least one dimension (see above) the ratio of the total number of welloff dimensions compared to the maximum possible number - the multidimensional headcount ratio - is distinctly lower at around $14-15 \%$ if it is sufficient to be well-off in at least one dimension $(\mathrm{k}=1)$. This is due to the fact that individuals with exactly one affluence count are predominant. In a similar way we can compare the fraction in the population with at least two well-off dimensions (9-10\%) with the resulting multidimensional index for $\mathrm{k}=2$ for which we again find a lower value of $6-6.5 \%$. When the cutoff on the second stage takes on the number of dimensions - in this case $\mathrm{k}=3$ - the simple headcount ratio $\mathrm{HR}(\mathrm{k})$ and the multidimensional index $\operatorname{HR}^{\mathrm{M}}(\mathrm{k})$ are identical. As mentioned before, we find that about $1 \%$ of the population happens to be well-off in income, health and life satisfaction at the same time.

Table 3: $\quad$ Well-off counts and dimension adjusted headcount ratio

\begin{tabular}{cccc}
\hline \hline & & $\mathbf{2 0 0 2}$ & $\mathbf{2 0 0 7}$ \\
\hline \% well-off & 1 & 24.7 & 25.5 \\
in ... dimensions & 2 & 8.5 & 7.8 \\
& 3 & 1.3 & 1.1 \\
\hline $\mathrm{HR}^{\mathrm{M}}(\mathrm{k})$ & $\mathrm{k}=1$ & 0.149 & 0.142 \\
& $\mathrm{k}=2$ & 0.066 & 0.059 \\
& $\mathrm{k}=3$ & 0.012 & 0.010 \\
\hline \hline
\end{tabular}

Source: SOEP, own calculations. 
In addition, we find that the multidimensional indices remain rather stable over time and only slightly decrease. This is opposite to the development of the onedimensional fraction of the well-off population in terms of income which increased between 2002 and 2007 (cf. Table 1). Hence, this illustrates that a multidimensional approach reveals different insights in the distribution of well-being. While the distribution of income has become more concentrated at the top, the concentration at the top of the multidimensional distribution has (slightly) decreased.

Contributions to multidimensional well-being. Finally, we provide evidence on the relative importance of the three dimensions under consideration. Figure 1 displays the percentage contribution to the total level of the multidimensional headcount index. ${ }^{4}$ We find that for $\mathrm{k}=1$ health contributes about a half to the total result while the contribution of income and overall life satisfaction are around $20 \%$ and $30 \%$ respectively. This means that about $50 \%$ of the counts contributing to the index $\mathrm{HR}^{\mathrm{M}}(\mathrm{k}=1)$ are due to very good health and to a much lesser extent to high income or a very high level of satisfaction with life in general. However, when increasing the requirement of the number of well-off dimensions to $k=2$ the importance of health remains large but decreases slightly to around $40 \%$. Instead, life satisfaction becomes more important with a contribution of clearly above $30 \%$. Taken together, well-off counts in life satisfaction and health make up almost $80 \%$ of the index. When the level of the second stage cutoff is set at its maximum value $\mathrm{k}=3$ the importance of all dimensions is more or less equally distributed and increases substantially for income.

\footnotetext{
${ }^{4}$ Figure 1 displays the results for the year 2007. The graph looks very similar for 2002 and is not presented here.
} 


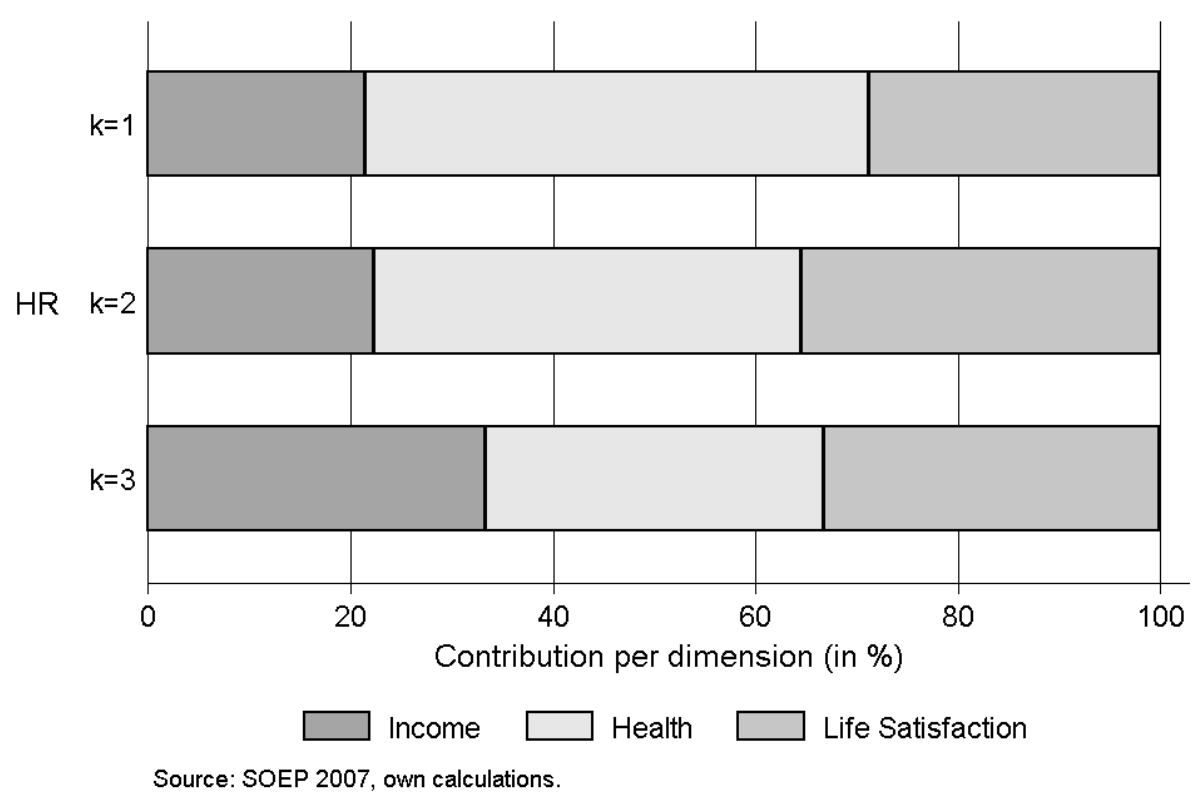

Figure 1: Contributions per dimension.

\section{Discussion}

Selection and weighting of dimensions. A multidimensional approach to measurement of economic well-being requires the researcher to take two decisions concerning the selection of dimensions that should be considered (cf. Decancq and Lugo, 2011a,b). First, one has to decide which dimensions arguably contributing to well-being should be taken into account at all. Implicitly, selected dimensions receive a strictly positive weight and dimensions that are not selected receive a weight of zero. Second, given the extensive decision to assign a positive weight to a dimension, the question is what this weight should be in relation to the other dimension under consideration.

In this paper, we selected three dimensions that are frequently used when analyzing well-being in a multidimensional setting (cf. Anand et al., 2009). We use income as the key economic indicator for material living standards but also take into account non-financial aspects of quality of life (health) as well as the subjective evaluation of life in general ("experienced utility"). However, the list of possible alternatives or extensions is long. Stiglitz et al. (2009) have summarized key dimensions that should in principle be taken into account. Among others, they recommend including wealth as a measure of sustainability in addition to assessing current well-being only. 
Moreover, especially when focusing at the top of a multidimensional distribution, wealth should be considered since "the rich" are not a homogeneous group with respect to income and wealth (Atkinson, 2008; Waldenström, 2009). In addition, the level of education can also be considered as a dimension of well-being. Clearly, education is the most important input in the "production" of earnings (cf. Card, 1999) and one could argue that education does not yield utility flows itself. However, education can additionally be interpreted in conjunction with "educated leisure" as an argument in an agent's utility function related to quality (cf. Llavador et al., 2011). Peichl and Pestel (2011) consider wealth and in an earlier version also education (Peichl and Pestel, 2010) as additional dimensions in the multidimensional approach applied in this paper. Accounting for these additional would be in principle possible here as well but there the correlation structure is more complex and, therefore, the weighting scheme becomes much more important. ${ }^{5}$

In this paper, we do not give different weights to the three dimensions but employ equal weighting, which is the simplest solution and easiest to interpret. This "intensive decision" with respect to the relative weighting of the dimensions under consideration is the second choice a researcher has to face, after having selected the dimensions. Every weighting scheme - including the naïve equal weights - implies a normative decision concerning the relative importance of dimensions, which might not reflect society's evaluation and should be open to public debate (cf. Anand and Sen, 1997). At the same time, there are multiple approaches to determine alternative weighting schemes and there is no agreement in the literature on multidimensional poverty and inequality. Decancq and Lugo (2011b) categorize data-driven, normative and hybrid approaches and critically survey several variants of them. Decancq et al. (2011) empirically show that equal weighting even turns out to be least supported by survey respondents.

Distribution. In our empirical application, we classified individuals dimensionspecifically as well as multidimensionally well-off based on binary decisions whether individual achievements within dimensions under consideration exceeded certain thresholds or not. Based on this, we computed the multidimensional headcount ratio for the top of the joint distribution. Thereby, we treat the multidimensional

\footnotetext{
${ }^{5}$ In addition, it is not clear whether education should not rather be regarded as an input rather than an outcome variable.
} 
distribution among the underlying population in a rather coarse way since it is divided into well-off and not well-off. This means, we do not take into account the distribution of dimensions beyond the cutoffs. However, multidimensional well-being can be assumed to be affected quite differently across the (joint) distribution of dimensions. That is why Stiglitz et al. (2009) recommend accompanying the analysis of average and median measures of living standards with indicators of their distribution. The analytical framework of Peichl and Pestel (2011) applied here allows taking into account the inequality at the top of the joint distribution. In a cross country analysis they find that wealth drives inequality among the top in Germany, while income is more important in the US. Hence, this reveals also interesting insights into the composition of the multidimensional rich population. However, we refrain from using these intensity measures here as life satisfaction is measured in an ordinal and not cardinal domain.

Data quality and requirements. A crucial precondition for performing a multidimensional analysis of well-being - i.e. the joint distribution of dimensions - is the availability of appropriate information. Most importantly, as elaborated in Alkire and Foster (2011b), the underlying data source needs to contain information on all dimensions under consideration and must be linked on the individual (or household) level. Typically, administrative data (like tax return data) contain detailed and reliable information on representative samples of the population on specific dimensions (e.g. on gross incomes and tax liabilities). At the same time, administrative data only have scarce information on other dimensions of interest and the household context. In contrast, many survey data sets provide information on a range of dimensions including respondents' subjective evaluations of various domains of life as well as conditions and capabilities. However, surveys are prone to measurement error and sometimes less representative for the entire population of interest. Hence, with regard to the growing interest in multidimensional analyses of well-being from both researchers and policy-makers, the data infrastructure should be extended in two directions. First, administrative data sources should contain or be linked to as many indicators and background information as possible. Second, survey data already containing information on sizeable numbers of dimensions should be increased in terms of number of observations, especially at the tails of the distribution. 


\section{Conclusions}

In this paper, we employ a multidimensional approach to measure well-being at the top of the joint distribution. In our empirical analysis, we use German micro data from the SOEP for the years 2002 and 2007 and three different types of dimensions that are considered as important contributors to well-being. We use income as the traditional indicator for material well-being, health as a proxy for non-material quality of life as well as self-reported satisfaction with life in general.

We find that one third of the population is well-off in at least one dimension but only one percent in all three dimensions simultaneously. While the distribution of income has become more concentrated at the top, the concentration at the top of the multidimensional distribution has decreased. Moreover, health as well as life satisfaction turn out to contribute quite substantially to multidimensional well-being at the top.

Our analysis shows that it is important to take into account other dimensions of wellbeing besides income - also at the top of the distribution. This is important in the current policy debate about the income and wealth concentration among the top $1 \%$ of the distribution. If income is not very important for their overall well-being, higher taxation (e.g. to reduce government debt) would not lead to (large) efficiency losses. 


\section{References}

Alkire, S. and J. Foster (2011a). Counting and Multidimensional Poverty Measurement. Journal of Public Economics 95 (7-8), 476-487.

Alkire, S. and J. Foster (2011b). Understandings and Misunderstandings of Multidimensional Poverty Measurement. Journal of Economic Inequality 9 (2), 289314.

Anand, S. and A. K. Sen (1997). Concepts of Human Development and Poverty: A Multidimensional Perspective, Human Development Papers, Human Development Report Office (UNDP), New York.

Anand, P., C. Santos and R. Smith (2009). The Measurement of Capabilities, in: K. Basu and R. Kanbur: Arguments for a Better World - Essays in Honor of Armataya Sen, Vol. 1, Oxford University Press, Oxford.

Anand, P. and M. van Hees (2006). Capabilities and Achievements: An Empirical Study, Journal of Socio-Economics 35, 268-284.

Atkinson, A. B. (2003). Multidimensional Deprivation: Contrasting Social Welfare and Counting Approaches. Journal of Economic Inequality 1 (1), 51-65.

Atkinson, A. B. (2008). Concentration among the Rich. in: J. B. Davies, Personal Wealth from a Global Perspective. Oxford University Press, Oxford.

Atkinson, A. B. and T. Piketty (2007). Top Incomes over the Twentieth Century. Oxford University Press, Oxford.

Atkinson, A. B., T. Piketty, and E. Saez (2011). Top Incomes in the Long Run of History. Journal of Economic Literature 49 (1), 3-71.

Bach, S., G. Corneo, and V. Steiner (2009). From Bottom to Top: The Entire Income Distribution in Germany, 1992-2003. Review of Income and Wealth 55 (2), 303-330. 
Barry, B. (2002). Social Exclusion, Social Isolation, and the Distribution of Income, in: J. Hills, J. L. Grand, and D. Piachaud, Understanding Social Exclusion, Oxford University Press, Oxford.

Blanchflower, D. G. and A. J. Oswald (2011): International Happiness, Working Paper, January 2011.

Bourguignon, F. and S. R. Chakravarty (2003). The Measurement of Multidimensional Poverty. Journal of Economic Inequality 1 (1), 25-49.

Card, D. (1999). The Causal Effect of Education on Earnings, in: O. Ashenfelter, and D. Card, The Handbook of Labor Economics Vol. III, North Holland, Amsterdam.

Decancq, K. and M. A. Lugo (2011a). Inequality of Well-Being: A Multidimensional Approach. Economica, forthcoming.

Decancq, K. and M. A. Lugo (2011b). Weights in Multidimensional Well-Being: An Overview. Econometric Reviews, forthcoming.

Decancq, K., L. Van Ootegem, E. Verhofstadt (2011). What if we voted on the weights of a multidimensional well-being index? An illustration with Flemish data, mimeo.

Foster, J., J. Greer, and E. Thorbecke (1984). A Class of Decomposable Poverty Measures. Econometrica 52 (3), 761-766.

Frick, J. R., J. Goebel, M. M. Grabka, O. Groh-Samberg, and G. G. Wagner (2007). Zur Erfassung von Einkommen und Vermögen in Haushaltssurveys: Hocheinkommensstichprobe und Vermögensbilanz im SOEP. SOEPpaper on Multidisciplinary Panel Data Research No. 19. 
Grabka, M. M. (2009). Codebook for the PEQUIV File 1984-2008. CNEF Variables with Extended Income Information for the SOEP. Data Documentation 45, DIW Berlin.

Llavador, H., J. E. Roemer, J. Silvestre (2011). A Dynamic Analysis of Human Welfare in a Warming Planet, Journal of Public Economics, 95 (11-12), 1607-1620.

Nübling, M., H. H. Andersen, A. Mühlbacher, J. Schupp, and G. G. Wagner (2007): Computation of Standard Values for Physical and Mental Health Scale Scores Using the SOEP Version of SF12v2, Schmollers Jahrbuch - Journal of Applied Social Sciences, 127(1), 171-182.

Peichl, A., T. Schaefer, and C. Scheicher (2010). Measuring Richness and Poverty: A Micro Data Application to Europe and Germany. Review of Income and Wealth 56 (3), 597-619.

Peichl, A. and N. Pestel (2010). Multidimensional Measurement of Richness: Theory and an Application to Germany, IZA Discussion Paper No. 4825.

Peichl, A. and N. Pestel (2011). Multidimensional Affluence: Theory and Applications to Germany and the US, IZA Discussion Paper No. 5926.

Piketty, T. (2005). Top Income Shares in the Long Run: An Overview. Journal of the European Economic Association 3 (2-3), 382-392.

Piketty, T. and E. Saez (2006). The Evolution of Top Incomes: A Historical and International Perspective. American Economic Review, Papers and Proceedings 96 (2), 200-205.

Socio-Economic Panel (2011). Data for Years 1984-2010, Version 27, SOEP.

Stiglitz, J. E., A. Sen, and J.-P. Fitoussi (2009). Report by the Commission on the Measurement of Economic Performance and Social Progress, Paris. 
Wagner, G. G., J. R. Frick, and J. Schupp (2007). The German Socio-Economic Panel Study (SOEP) - Scope, Evolution and Enhancements. Schmollers Jahrbuch - Journal of Applied Social Sciences 127 (1), 139-169.

Waldenström, D. (2009). Lifting All Boats? The Evolution of Income and Wealth Inequality over the Path of Development, Lund Studies in Economic History 51. 